\title{
Nondestructive evaluation techniques for assessing dynamic modulus of elasticity of moso bamboo (Phyllosachys edulis) lamina
}

Received: July 13, 2005 / Accepted: September 21, 2005 / Published online: March 2, 2006

\begin{abstract}
Bamboo, an extensively used material in Asia, is becoming an increasingly available structural (e.g., flooring and furniture) material in Taiwan. The bending strength and dynamic modulus of elasticity of moso bamboo (Phyllosachys edulis) laminae were investigated using ultrasonic-wave and drilling resistance techniques. The strength quality of bamboo was reduced after steaming treatment and was significantly affected by node characteristics. The transverse variations of the mean drilling resistance value $(R)$ gradually increased outward from the bamboo cavity layer. There were very significant positive relationships among density $(\rho)$, the drilling resistance value $(R)$, the dynamic modulus of elasticity $(\mathrm{Eb})$, the modulus of elasticity (MOE), and the modulus of rupture (MOR), although the coefficients of determination were small. Combining ultrasonic-wave and drilling resistance techniques is efficient in estimating and establishing the dynamic modulus of elasticity (REb). Values of REb for moso bamboo increased with increasing $\rho, R, \mathrm{~Eb}, \mathrm{MOE}$, and MOR, and the relationships could each be represented by positive linear regression formulas.
\end{abstract}

Key words Moso bamboo (Phyllosachys edulis) · Lamina · Ultrasonic wave $\cdot$ Drilling resistance

\section{Introduction}

Yoshinaga $^{1,2}$ pointed out that the depletion of global resources is due to the rapid increase in wood consumption and the lack of planned forest management. At present, the

C.-J. Lin $(\square)$

Division of Forest Utilization, Taiwan Forestry Research Institute,

53 Nan-Hai Rd, Taipei 100, Taiwan

Tel. +88-622-3039978 (ext 2604); Fax +88-622-3035738

e-mail: d88625002@yahoo.com.tw

M.-J. Tsai · S.-Y. Wang

Department of Forestry, College of Agriculture, National Taiwan

University, Taipei 106, Taiwan development and advanced utilization of multipurpose tree and bamboo plantations is vital to meeting the demands for woody materials. After plantation wood, bamboo is a promising material due to its fast growth and the shortage of wood supplies. In 3-5 years, the mechanical strength, utilization properties, and anatomical characteristics of bamboo become stable and mature, making it suitable for various uses. The effective utilization of bamboo (laminae) requires an understanding of its properties.

Moso bamboo (Phyllostachys edulis) is an important and potential forest resource in Taiwan. In order to develop an innovative processing system that can markedly increase the value of utilization of bamboo, researchers and manufacturers have engaged in serial studies on moso bamboo, in an attempt to utilize it as stock for quality furniture and floor making. For example, maximum recovery of bamboo pieces, effects of preservation and dyeing treatment, curvature of bamboo pieces, optimum curing conditions of the glueline, laminated bending mechanical and finishing properties, and the technology of manufacturing laminated bamboo furniture have been explored. ${ }^{3-5}$ Lee et al. ${ }^{6,7}$ indicated that many properties of bamboo are similar to those of wood, and bamboo has been experimentally used to manufacture a variety of engineered composite products (e.g., strandboard and laminated lumber).

During the past 20 years, wood scientists and the forest products industry have developed and used nondestructive testing (NDT) tools for a wide range of applications, from wood-based materials (composite products, lumber, logs) to the evaluation of standing trees. For instance, ultrasonic wave and drilling resistance methods are two useful, nondestructive techniques for estimating the physical properties of a material. From these efforts evolved a hypothesis, founded on fundamental material properties, for establishing the relationships between NDT parameters and static mechanical properties/density of wood products. ${ }^{8-12}$ The applicability of these two methods for assessing the quality of wood materials has been extensively investigated, although not with bamboo materials.

Currently, there is interest in developing and using costeffective technologies to evaluate bamboo-based materials 
(laminae or laminated bamboo products). In particular, several studies have shown a good relationship between the dynamic modulus of elasticity and the static modulus of elasticity of lumber cut from trees. ${ }^{13-16}$ These encouraging results led us to hypothesize that the use of the nondestructive technique may be useful in assessing bamboo lamina quality.

The density $(\rho)$, dynamic modulus of elasticity $(\mathrm{Eb})$, modulus of elasticity (MOE), and modulus of rupture (MOR) are the most common properties used to indicate the strength quality for construction. They are very important factors in determining the strength of bamboo. Traditionally, studies have concentrated on the bamboo properties determined by destructive testing. However, research is lacking in the use of nondestructive evaluation techniques. Therefore, this study investigated the $\mathrm{Eb}$, MOE, and MOR of moso bamboo laminae using the ultrasonic-wave method and static bending test, as well as the drilling resistance value of the laminae by the drilling resistance technique. Moreover, Eb was evaluated by combining ultrasonic-wave and drilling resistance (for established density) techniques. Relationships between different bamboo lamina properties were also examined by the two NDT methods. The results provide basic information for future bamboo research, processing, and utilization.

\section{Materials and methods}

\section{Experimental materials}

Moso bamboo culm was sliced into strips of four different laminae, including node material without steam treatment (A), node material with steam treatment (B), internode material without steam treatment (C), and internode material with steam treatment $(\mathrm{D})$, and the samples were tested in this study. The bamboo laminae were boiled in a solution $\left(30 \% \mathrm{H}_{2} \mathrm{O}_{2}, 100^{\circ} \mathrm{C}, 6-8 \mathrm{~h}\right)$ to reduce the starches and sugars that would otherwise attract termites or beetles, and steamed (carbonized) under heat and pressure $\left(3.5 \mathrm{~kg} / \mathrm{cm}^{2}\right.$, $\left.145^{\circ} \mathrm{C}, 90 \mathrm{~min}\right)$ to darken the color. Thirty specimens were prepared from each type of material for each set of experiments. The dimensions of each specimen of bamboo lamina were 20 (longitudinal) $\times 2.5$ (tangential) $\times 0.7 \mathrm{~cm}$ (radial). The specimens were conditioned in a controlledenvironment room at $20^{\circ} \mathrm{C}$ and $65 \%$ relative humidity (RH).

\section{Ultrasonic-wave test}

The density and ultrasonic velocity of specimens were measured and calculated. Ultrasonic velocities and $\mathrm{Eb}$ were measured using a portable ultrasonic nondestructive testing Pundit (CNC Electronic, London) meter, at a frequency of $54 \mathrm{kHz}$. Specimens were placed between the transmitting and receiving transducers, and the travel time of the ultrasonic wave (transmission time) was displayed on the meter screen and recorded (Fig. 1). Eb was calculated using the ultrasonic wave velocity and the density of the specimen.

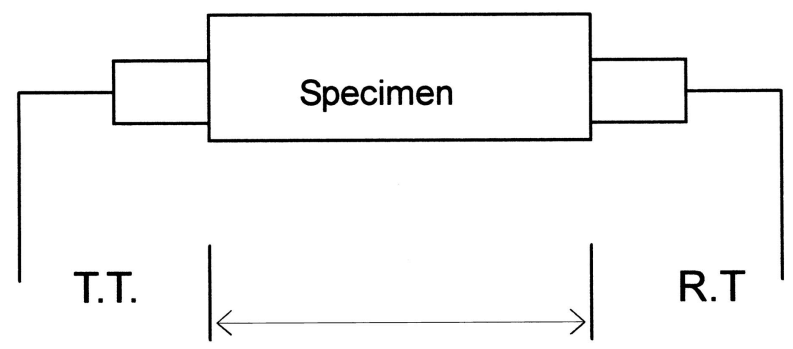

\section{$\mathrm{L}$, Fiber direction}

Fig. 1. Measurement method for ultrasonic velocity and dynamic modulus of elasticity of bamboo lamina. $L$, Length of specimen; T.T., transmitting transducer; R.T., receiving transducer

Drilling resistance test

The Resistograph instrument is known as a suitable and efficient tool for estimating the growth trends of trees. Mean levels of resistance charts are closely correlated to the density of the dry wood, with $r^{2}$ (coefficient of determination) values over $0.8 .^{12,17,18}$ Furthermore, typical tree-ring variations in the resistance chart are very similar to those in the X-ray microdensity chart. ${ }^{11,17}$

The drilling resistance technique was used to measure the density profiles of the moso bamboo lamina samples. The Resistograph (3450-S; Frank Rinn, Germany) drives a slender bit into the lamina and measures the drilling resistance as it rotates. Drilling was performed in the radial direction. The needle bit had a shaft diameter of $1.5 \mathrm{~mm}$ and a maximum length of $450 \mathrm{~mm}$. The drilling resistance is concentrated at the tip because the width is double the diameter of the shaft $(3 \mathrm{~mm})$. Using a linear relationship between the drilling resistance value and the density as reported by Winistorfer et al., ${ }^{11}$ the following relationship was established where $n$ is the number of data points recorded in one resistance profile measurement, $D$ is the average board density, $c$ is the coefficient relating the resistance value and the density value, and $R$ is the drilling resistance value.

The coefficients relating to the point density were then estimated by the following equations

$D=\sum_{i=1}^{n} \frac{D_{i}}{n}=c \times \sum_{i=1}^{n} \frac{R_{i}}{n} ;$

$c=n \times \frac{D}{\sum_{i=1}^{n} R_{i}} ;$

and

$D_{i}=c \times R_{i}(i=1$ to $n)$.

The drilling resistance values (profiles) were obtained using the Decom 2.16 program. The analysis of characteristics was made according to the hypothesis that there is a 
positive relationship between density and the drilling resistance values. The drilling resistance technique was then used to measure the density profiles of the bamboo samples.

In this experiment, the drilling resistance values $(R)$ for moso bamboo increased with increasing bamboo density $(\rho)$, and the relationship could be represented by positive linear regression formulas of the form

$$
\rho=1.56(\text { c value }) \times R+268.2, \quad r^{2}=0.35, \quad F=64.3^{* *}
$$

The nature of the relationship is in accordance with other reports (wood composite panel and Taiwania wood), ${ }^{11,18}$ however, the coefficient of determination $\left(r^{2}=0.35\right)$ obtained from this study was lower.

\section{Static bending test}

The static bending test was conducted in accordance with the center loading method for bamboo specimens (laminae), using a Shimadzu UH-10A universal-type testing machine. All specimens were placed flat for the bending tests, and the span was $18 \mathrm{~cm}$ for the specimens (Fig. 2). The proportional limit, ultimate load, and the deflection were obtained from the load-deflection curves, and the MOE and MOR were calculated.

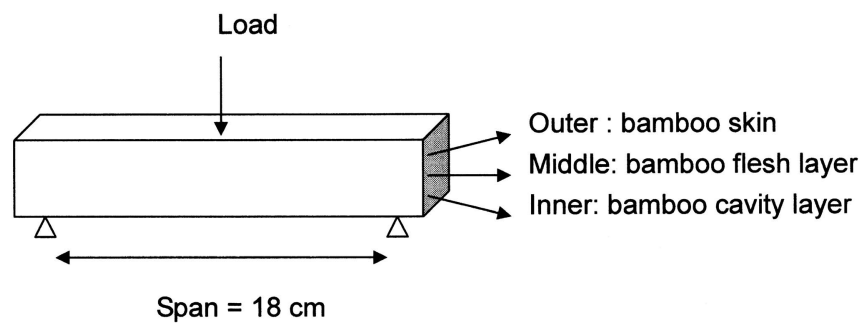

Fig. 2. Configuration of the static bending test for bamboo lamina
Hardness test

In accordance with CNS $460,{ }^{19}$ the hardness of all specimens in the bamboo skin side (radial surface) was tested after reaching Equilibrium Moisture Content at 65\% RH.

\section{Results and discussion}

Bamboo density and dynamic modulus of elasticity

The mean density $(\rho)$ and dynamic modulus of elasticity (Eb) of the node material without steam treatment (laminae A), node material with steam treatment (laminae B), internode material without steam treatment (laminae C), and internode material with steam treatment (laminae D) are summarized in Table 1. The mean $\rho$ and Eb values of laminae $\mathrm{C}$ were greatest among the four materials used in this study. However, Duncan's multiple-range test indicated that the mean $\rho$ and Eb values of specimens $\mathrm{A}$ and $\mathrm{C}$ did not differ significantly, while those between the other specimens were all significantly different. In other words, variations in average $\rho$ and $\mathrm{Eb}$ in the four kinds of specimens showed the following trend: specimens $\mathrm{C}$ and $\mathrm{A}>$ specimen $\mathrm{D}>$ specimen B. It was found that the average values of $\rho$ and $\mathrm{Eb}$ in the bamboo laminae obtained from specimens without steam treatment were significantly higher than those from specimens subjected to steam treatment. It is speculated that heating of the bamboo strips during the carbonization process may alter its chemical components. This result was similar to that in the report of Tang, ${ }^{4}$ who indicated that steam treatment has a negative effect on the strength properties of bamboo.

Modulus of elasticity (MOE) and modulus of rupture (MOR)

The mean MOE and MOR of laminae A, B, C, and D are also shown in Table 1. The mean MOE and MOR of the

Table 1. Bending properties of moso bamboo (Phyllosachys edulis) laminae

\begin{tabular}{|c|c|c|c|c|}
\hline \multirow[t]{2}{*}{ Parameter } & \multicolumn{4}{|l|}{ Type of laminae } \\
\hline & A & B & $\mathrm{C}$ & $\mathrm{D}$ \\
\hline Moisture content (\%) & $11.9(0.3)$ & $11.7(0.4)$ & $12.1(0.4)$ & $11.5(0.3)$ \\
\hline$\rho\left(\mathrm{kg} \mathrm{m}^{-3}\right)$ & $780 \mathrm{c}(73)$ & $664 a(83)$ & $800 \mathrm{c}(82)$ & $712 b(49)$ \\
\hline$V\left(\mathrm{~m} \mathrm{~s}^{-1}\right)$ & $4366.8(152.6)$ & $4374.6(181.8)$ & $4357.3(207.2)$ & $4423.9(209.4)$ \\
\hline $\mathrm{Eb}(\mathrm{MPa})$ & $14845.8 \mathrm{c}(1290.3)$ & $12666.1 \mathrm{a}(1507.2)$ & $14930.0 \mathrm{c}(1040.5)$ & 13918.9b (1117.9) \\
\hline $\mathrm{MOE}(\mathrm{MPa})$ & $10918.6 \mathrm{c}(734.4)$ & 8991.6a (1014.6) & $11507.2 \mathrm{~d}(805.2)$ & $9957.5 b(747.8)$ \\
\hline MOR (MPa) & $128.3 b(14.2)$ & $100.5 \mathrm{a}(16.6)$ & $144.3 \mathrm{c}(9.6)$ & $124.3 b(10.9)$ \\
\hline$R$ & - & - & $304.3(35.4)$ & $300.5(33.6)$ \\
\hline$H\left(\mathrm{~kg} / \mathrm{mm}^{2}\right)$ & - & - & $3.20(0.69)$ & $2.89(0.60)$ \\
\hline
\end{tabular}

Values in parentheses represent standard deviations

A, node material with no treatment; $\mathrm{B}$, node material with steam treatment; $\mathrm{C}$, internode material without treatment; $\mathrm{D}$, internode material with steam treatment; $\rho$, Air-dried density; $V$, ultrasonic wave velocity; Eb, dynamic modulus of elasticity; MOE, modulus of elasticity; MOR, modulus of rupture; $R$, drilling resistance value; $H$, hardness

Different letters $(\mathrm{a}-\mathrm{d})$ within a row indicate significant difference by Duncan's multiple range test, $P<0.05$ 
laminae $\mathrm{C}$ were the greatest among the four materials used in this study. However, Duncan's multiple-range test indicated that the mean MOR values of specimens $\mathrm{A}$ and $\mathrm{D}$ did not differ significantly, while those between the other specimens were all significantly different. In other words, variations in the four kinds of specimens showed the following trend: specimen $\mathrm{C}>$ specimen $\mathrm{A}>$ specimen $\mathrm{D}>$ specimen $\mathrm{B}$ (average MOE) and specimen $\mathrm{C}>$ specimens $\mathrm{A} / \mathrm{D}>$ specimen B (average MOR). It was found that the average values of the MOE and MOR in the bamboo laminae obtained without steam treatment and internode specimens were significantly higher than those with steam treatment and node specimens, respectively. This is similar to the result of Jai, ${ }^{5}$ who indicated that the strength of bamboo is reduced after steaming treatment.

Moreover, node portions of the bamboo weaken the strength of bamboo material when compared with the clear sections of the bamboo culm. ${ }^{4}$ Bamboo quality is significantly affected by node characteristics. Detection of nodes in bamboo is especially important because nodes are numerous and are the most severe defects. Reductions in strength, and in processing and dimensional stability associated with the number and position of nodes are often qualitatively attributed to differences (property variations) in bamboo quality between node and internode materials.

Relationships between density and mechanical properties

Values of Eb, MOE, and MOR for bamboo increased with increasing density $(\rho)$, and the relationships could be represented by positive linear regression formulas (Table 2). The results are similar to those reported earlier by Wang and Lin, ${ }^{20}$ Wang and Ko ${ }^{10}$ and Wang et al ${ }^{21}$ that were obtained from small-diameter logs of Japanese cedar, China fir, and Taiwania wood, respectively.

Table 2. Coefficients of linear regression formulas $(Y=a X+b)$ for the correlation between bending properties and drilling resistance values

\begin{tabular}{|c|c|c|c|c|c|}
\hline \multicolumn{4}{|c|}{ Coefficients } & \multirow[t]{2}{*}{$r^{2}$} & \multirow[t]{2}{*}{$F$ value } \\
\hline$Y$ & $X$ & $a$ & $b$ & & \\
\hline $\mathrm{Eb}$ & $\rho$ & 16.5 & 2808.6 & 0.68 & $248.4 * *$ \\
\hline MOE & $\rho$ & 10.3 & 2767.3 & 0.54 & $136.4 * *$ \\
\hline MOR & $\rho$ & 0.13 & 27.5 & 0.34 & $60.2 * *$ \\
\hline MOE & $\mathrm{Eb}$ & 0.60 & 1284.4 & 0.75 & $349.9 * *$ \\
\hline MOR & $\mathrm{Eb}$ & 0.01 & -3.82 & 0.58 & $161.3^{* *}$ \\
\hline MOR & MOE & 0.01 & -12.9 & 0.68 & $250.0 * *$ \\
\hline $\mathrm{Eb}$ & $R$ & 28.6 & 6384.4 & 0.29 & $49.3 * *$ \\
\hline MOE & $R$ & 16.2 & 5454.1 & 0.19 & $28.4 * *$ \\
\hline MOR & $R$ & 0.23 & 54.8 & 0.15 & $21.1 * *$ \\
\hline $\mathrm{REb}$ & $R$ & 86.7 & -11162.1 & 0.88 & $892.1 * *$ \\
\hline$\rho$ & $\mathrm{REb}$ & 0.013 & 536.9 & 0.22 & $33.9 * *$ \\
\hline $\mathrm{Eb}$ & $\mathrm{REb}$ & 0.36 & 9668.4 & 0.39 & $75.3 * *$ \\
\hline MOE & $\mathrm{REb}$ & 0.20 & 7381.2 & 0.24 & $38.2 * *$ \\
\hline MOR & $\mathrm{REb}$ & 0.007 & 21.3 & 0.24 & $37.6 * *$ \\
\hline
\end{tabular}

$r^{2}$, Coefficient of determination; $R E b$, dynamic modulus of elasticity calculated from the drilling resistance value

$* * P<0.01$

\section{Correlations among mechanical properties}

Correlations between the mechanical properties $(\mathrm{Eb}$, MOE, and MOR) of moso bamboo laminae could be represented by positive linear regression formulas (Table 2 ). The coefficients of determination $\left(r^{2}\right)$ were highly significant at the 0.01 level, as indicated by the $F$ value test. These results are in agreement with many previous studies ${ }^{10,20,21}$ in plantation trees.

\section{Drilling resistance values and hardness}

The mean drilling resistance values $(R)$ of laminae $\mathrm{C}$ and $\mathrm{D}$ are shown in Table 1. Duncan's multiple-range test indicated that the mean $R$ values of specimens A and D did not differ significantly. In other words, the mean $R$ values of internode material without steam treatment and with steam treatment were similar.

The bamboo cavity layer-to-bamboo skin radial variation patterns of $R$ for moso bamboo are presented in Fig. 3. In this experiment, the transverse variation of the mean $R$ increased from the inner bamboo cavity layer outward to the outer bamboo skin. In other words, $R$ gradually increased from the bamboo cavity layer outward.

In accordance with CNS $460,{ }^{19}$ the hardness of specimens with and without steam treatment was tested. The mean hardness of natural bamboo laminae (C) did not significantly differ from that of steamed bamboo laminae (D), indicating that the hardness of bamboo lamina might not be greatly affected by the carbonization treatment used to darken bamboo laminae color (Table 1).

Lee and $\mathrm{Liu}^{22}$ indicated that the mean specific gravity and hardness of natural and carbonized bamboo products do not differ significantly. However, $\mathrm{Tang}^{4}$ indicated that the specific gravity and hardness of bamboo are reduced after carbonizing treatment. Tang also indicated that steam treatment has a varied effect on the strength properties of bamboo. Hence, in this study, the properties of bamboo are affected by various levels of steaming processes (carbonizing).

The power consumption of the drilling device was electronically measured relative to the drilling resistance. The density profile can be calculated by converting the drilling resistance values via a linear equation. The tissue structure

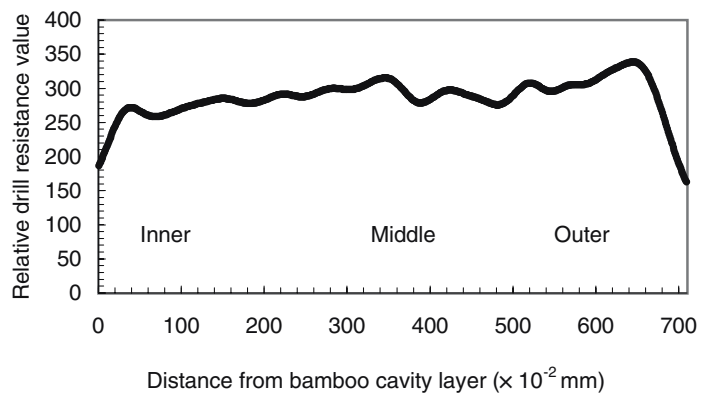

Fig. 3. Drilling resistance record measured from a bamboo sample 
of bamboo differs from that of wood. For example, vascular bundles of leptomorph rhizome species possess a central vascular strand only. Owing to the tissue structure variation of bamboo, drilling resistance values may be influenced by various steam processes. In addition, the strength properties of bamboo material vary with the age of the bamboo plant and the longitudinal position of the bamboo culm. In summary, the properties (e.g., $R$ and MOR) of moso bamboo are influenced by defects (nodes), anatomic characteristics (vascular bundles), steam treatment, and other effects.

Relationships between drilling resistance value and bending properties

The drilling resistance values $(R)$ were measured and calculated from bamboo specimens, and substituted into Eq. 4 to calculate the bamboo (established) density $(\rho)$. In other words, density values could be calculated by converting drilling resistance values ( $R$ from the Resistograph) via a linear equation. Both $\rho$ and ultrasonic velocity ( $V$ from the Pundit) were measured and calculated from the bamboo specimens, and were substituted into Eq. 5 to calculate the dynamic modulus of elasticity (REb).

$\mathrm{REb}(\mathrm{MPa})$ was calculated from the following formula:

$$
R E b=V^{2} \times(R \times C),
$$

where $V$ is the ultrasonic velocity, $R$ is the average drilling resistance value, $C$ (value $=1.56$ ) is the average coefficient relating the resistance value and density (constant), and $(R \times C)$ is the established density. With this method, one does not need to measure the weight and volume of a material. Therefore, it is relatively fast and easy to perform indirect dynamic modulus of elasticity measurements.

Values of Eb, MOE, MOR, and REb for moso bamboo laminae increased with an increase in the drilling resistance $(R)$, and the relationships can be represented by positive linear regression formulas (Table 2). However, except for $\operatorname{REb}\left(r^{2}=0.88\right)$, the coefficients of determination obtained in this study were low.

\section{Relationships between $\mathrm{REb}$ and bending properties}

The dynamic modulus of elasticity (REb) was calculated from Eq. 5, and the process involves combining the ultrasonic-wave method with the drilling resistance method. The weight and volume of a specimen do not need to be measured, but the coefficient $(C)$ must be calculated and determined in advance.

The method can be applied to wood-based products for which values cannot be calculated or for which the density is not easy to measure in order to estimate the physical properties (e.g., Eb) by combining the ultrasonic-wave and drilling resistance techniques.

Values of $\rho, \mathrm{Eb}, \mathrm{MOE}$, and MOR for moso bamboo laminae increased with an increase in $\mathrm{REb}$, and the rela- tionships can be represented by positive linear regression formulas (Table 2).

Their determination coefficients $\left(r^{2}\right)$ were low, and significant differences (at $P<0.01$ ) were found by the $F$-test. These results indicated that $\mathrm{MOE}\left(r^{2}=0.68\right), \mathrm{Eb}\left(r^{2}\right.$ $=0.58), \rho\left(r^{2}=0.34\right)$, and $\operatorname{REb}\left(r^{2}=0.24\right)$ were the most important predictors of moso bamboo lamina bending strength according to regression analyses. Some causes of the variation in results may be defects (nodes), anatomic characteristics (vascular bundles), steam treatment, the age of the bamboo plant, and the longitudinal position of the bamboo culm.

\section{Conclusions}

Bamboo is an important forest resource in Taiwan with considerable potential for further utilization. The bending properties and dynamic modulus of elasticity of moso bamboo (Phyllosachys edulis) laminae were investigated, with the following results:

1. The average values of the density $(\rho)$, dynamic modulus of elasticity (Eb), modulus of elasticity (MOE), and modulus of rupture (MOR) of bamboo laminae obtained from internode specimens and without steam treatment were significantly higher than those for node and steam-treated specimens.

2. The transverse variation in the mean drilling resistance values $(R)$ increased with increasing distance from the bamboo cavity layer.

3. The values of Eb, MOE, and MOR increased with increases in $\rho$ or drilling resistance $(R)$.

4. The proposed method combines ultrasonic-wave and drilling resistance techniques for estimating and establishing the dynamic modulus of elasticity (REb). Values of $\mathrm{REb}$ for moso bamboo increased with increasing $\rho, R$, $\mathrm{Eb}, \mathrm{MOE}$, and MOR.

Acknowledgment This project was funded by the Taiwan Forest Research Institute.

\section{References}

1. Yoshinaga K (1994) How to use bamboo effectively for the regrowth of a tropical rain forest. Rep Fuji Bamboo Gard 38:87-89

2. Yoshinaga K (1996) Developing way of capitalizing on the effectiveness of bamboos is essential to preserve the environment of the earth. Rep Fuji Bamboo Gard 40:133-136

3. Lu CM (1994) Resources and utilization of bamboo in Taiwan. Problem analysis on bamboo research in South East Asia. Proceedings of an International Workshop on Bamboo Research, Taiwan, pp 97-114

4. Tang JL (1989) Strength properties of bamboo material. J Taiwan Forest Prod Ind 8:65-78

5. Jai SY (1990) The manufacturing of Lamboo furniture. The utilization and processing of bamboo material. Forest Product Association of Taiwan, Taipei, Taiwan, pp 119-132

6. Lee A, Bai X, Peralta PN (1996) Physical and mechanical properties of strandboard made from giant timber bamboo. Forest Prod J 46:84-88 
7. Lee A, Bai X, Bangi AP (1998) Selected properties of laboratorymade laminated-bamboo lumber. Holzforschung 52:207-210

8. Bucur V (1995) Acoustics of wood. CRC, Boca Raton, FL, pp 185192

9. Peterson KR (1994) The role of nondestructive evaluation in assuring the wise use of our timber resource. NDT 1994 9th International Symposium on Nondestructive Testing of Wood, pp 7-9

10. Wang SY, Ko CY (1998) Dynamic modulus of elasticity and bending properties of large beams of Taiwan-grown Japanese cedar from different plantation spacing sites. Mokuzai Gakkaishii 44:6268

11. Winistorfer PM, Xu W, Wimmer R (1995) Application of a drill resistance technique for density profile measurement in wood composite panels. Forest Prod J 45:90-94

12. Wang SY, Chiu CM, Lin CJ (2003) Application of the drilling resistance method for annual ring characteristics evaluation of Taiwania (Taiwania cryptomerioides Hay.) trees grown in different thinning and pruning treatments. J Wood Sci 49:116-124

13. Ross RJ (1992) Nondestructive testing of wood. Proceedings of Nondestructive Evaluation of Civil Structures and Materials. University of Colorado Boulder, pp 43-46

14. Ross RJ, Brashaw BK, Pellerin RF (1998) Nondestructive evaluation of wood. Forest Prod J 48:14-19

15. Ikeda K, Arima T (2000) Quality evaluation of standing trees by a stress-wave propagation method and its application II. Evaluation of sugi stands and application to production of sugi (Cryptomeria japonica D. Don) structural square sawn timber. Mokuzai Gakkaishi 46:189-196
16. Nakamura N (1996) Measurement of the properties of standing trees with ultrasonics and mapping of the properties. Univ For Hokkaido Fac Agric Univ Tokyo J 96:125-135

17. Rinn F, Schweingruber FH, Schar E (1996) Resistograph and Xray density charts of wood comparative evaluation of drill resistance profiles and X-ray density charts of different wood species. Holzforschung 50:303-311

18. Lin CJ, Wang SY, Lin FC, Chiu CM (2003) Effect of moisture content on the drill resistance value in Taiwania plantation wood. Wood Fiber Sci 35:234-238

19. Chinese National Standard (CNS 460) (1995) Methods of test for hardness of wood. Bureau of Standards, Metrology, and Inspection, Taipei, Taiwan

20. Wang SY, Lin SH (1996) Effects of plantation spacing on the quality of visually graded lumber and mechanical properties of Taiwan-grown Japanese cedar. Mokuzai Gakkaishii 42:435-444

21. Wang SY, Lin CJ, Chiu CM, Chen JH, Yung TH (2005) Dynamic modulus of elasticity and bending properties of Taiwania young trees grown with different thinning and pruning treatments. J Wood Sci 51:1-6

22. Lee A, Liu Y (2003) Selected physical properties of commercial bamboo flooring. Forest Prod J 53:23-26

The publication of this article was made possible by an Emachu Research Fund. The authors are grateful for the fund. 